\title{
ALGUNOS HELMINTOS DE SCOMBER JAPONICUS «CABALLA» DE LA RESERVA NACIONAL DE PARACAS
}

RUFINO CABRERA CH. (1) MANUEL TANTALEÁN V. (2)

\author{
(1) Facultad d: Ciencias, Universidad Nacional San Luis Gonzaga de Ica. Casilla 03. Ica Perú. \\ (2) Instituto de Medicina Tropical»Daniel A. Carrión» UNMSM. Casilla 2670. Lima 100. Lima Perú.
}

\begin{abstract}
SUMMARY
In this paper, some helminths of Scomber japonicus «caballa» from the National Reserve of Paracas (Ica) are presented.S.japonicus is a new host for Corynosoma obtuscens larvae from the peruvian coast.

KEY WORDS: Helminths, caballa, Paracas, Ica.
\end{abstract}

\section{RESUMEN}

En este trabajo, presentamos algunos helmintos que parasitan a Scomber japonicus «caballa», de la Reserva Nacional de Paracas (Ica). S. japonicus es un nuevo huesped para larvas de Corynosoma obtuscens.

PALABRAS CLAVE: Helmintos, caballa, Paracas, Ica.

\section{INTRODUCCION}

Los helmintos de peces marinos no son muy conocidos en nuestra costa a pesar que algunas especies, ya sea en estado adulto o en forma larvaria afectan el recurso íctico o comprometen la salud del hombre (Mateo, 1972).

Se han citado algunos parásitos de «caballa» de las costas de Lambayeque, Lima, Trujillo y Arequipa en trabajos realizados por Malca y Suárez (1979), Luque (1991), Ruelas y Córdova (1994), Tantaleán y Huiza (1994); pero para las costas de Ica y especialmente para la Reserva Nacional de Paracas sólo nos enteramos de la existencia de larvas de Anisakis por la publicación de Cabrera (1994).

En el presente trabajo, como contribución al conocimiento de la fauna parasitaria de peces marinos de la costa del Perú, damos a conocer el hallazgo de algunos helmintos de «caballa» de la Reserva Nacional de Paracas, pez que se captura regularmente de manera artesanal y que se utiliza para la alimentación humana.

\section{MATERIAL Y METODOS}

Se examinaron 41 «caballas» procedentes de las Islas Chincha, Islas Ballestas y de las costas de Lagunillas y Laguna Grande, desembarcadas en el muelle San Andrés (Pisco).
Los metacéstodos, larvas de acantocéfalos y tremátodes se fijaron en formol al 5\%. Para identificarlos, se colorearon con carmín acético de Semichon y montaron en bálsamo de Canadá. Los nemátodes se fijaron en alcohol de $70 \%$ y se clarificaron en una mezcla de alcohol-fenol.

\section{RESULTADOS Y COMENTARIOS}

Nematobothrium scombri (Taschenberg, 1879)

Este es un platelminto que se asemeja a un nemátode por la forma del cuerpo y por su tamaño. Parasita las gónadas de las hembras originando severas alteraciones morfológicas y funcionales.

\section{Tentacularia coryphaenae Bosc,1802}

Se colectaron 2 larvas de la superficie visceral de 2 peces $(4.9 \%)$, procedentes de las Islas Ballestas y de Laguna Grande. Anteriormente se observaron éstas larvas en otros peces de las costas de Paita, Lambayeque, Callao, Chorrillos (Luque, 1991; Tantaleán y Huiza, 1994) y recientemente en peces de la costa Sur (Ruelas y Córdova, 1994).

Corynosoma obtuscens Lincicome, 1943

Se ubicaron formas juveniles en la superficie visceral y en el mesenterio de $3(7.3 \%)$ «caballas» procedentes de 
las Islas Chincha y Lagunillas. Esta especie se presenta en las costas de varias localidades parasitando a numerosos peces, pero no se le conocía en Scomber japonicus, por los que éste sería un nuevo huésped en el Perú.

\section{Anisakis (Larvas Tipo II)}

Descubrimos entre 1 y 16 larvas en la superficie visceral e hígado de 15 (36.5\%) «caballas» procedentes de Islas Ballestas, Lagunillas y Laguna Grande. Cabrera (1994) las encontró en el mismo huésped de Lagunillas. Observamos que la mayor infección se relaciona con la talla del pez (Principalmente en los tamaños comerciales), zona de pesca y estación del año (los peces provenían de aguas abiertas). Las larvas de Anisakis tipo II corresponden a $A$. physeteris; se les considera patógenas para el hombre (Ishikura et. al., 1992)

\section{REFERENCIAS BIBLIOGRAFICAS}

CABRERA, CH.R. 1994. Algunas consideraciones sobre la presencia de larvas de Anisakis en peces marinos. Revista Peruana Medicina Tropical UNMSM. 8:95-96.

ISHIKURA,H., KIKUCHI,K., NAGASAWA,K., OOIWA,T., TAKAMIYA,H., SATO,N. and SUGANE,K. 1992. Anisakidae and Anisakidosis. In: Sun
T. (Eds.) Progress in Clinical Parasitology, Vol III, pp.43-102 Springer Verlag, New York, Inc.

LUQUE, J.L.1991.Formas larvarias de helmintos parásitos en especies marinas del Perú. Parasitología al Dia 15: 43-48.

MALCA, T. y SUAREZ, c. 1979. Nemátodos parásitos en «caballa» Scomber japonicus peruanus J.H. 1925, desembarcado en la Caleta de Santa Rosa, Lambayeque. Libro Resumenes VI Congreso Peruano de Microbiología y Parasitología. Chiclayo -Perú.

MATEO, E. 1972. La Ictiopatología y su importante rol en la productividad pesquera. Universidad Nacional Federico Villarreal. Lima

RUELAS, N. y CORDOVA, B.E.1994. Tremátodes de Scomber japonicus del litoral Sur Peruano. Libro Resúmenes. XI Congreso Nac. Biología y V Simposio Nac. Educación en Ciencias Biológicas. Tacna, Perú, p. 169.

TANTALEAN V.M. y HUIZA, F.A. 1994. Sinopsis de los parásitos de peces marinos de la Costa Peruana. Biotempo, 1:53-101. 